http://revistaurbanismo.uchile.cl

\title{
La protección del patrimonio arqueológico
}

\author{
Luis Maldonado Ramos
}

\section{Filiación}

Dr. Arquitecto y Profesor Titular de la Universidad Politécnica de Madrid. Arquitecto en ejercicio desde 1984, es profesor del Departamento de Construcción y Tecnología Arquitectónicas de la Escuela Técnica Superior de Arquitectura de Madrid, donde enseña Construcción. Actualmente es profesor del Programa Doctoral Universidad Politécnica de Madrid - Universidad de Chile.

\section{Fernando Vela Cossío}

\section{Filiación}

Arqueólogo, profesión que ejerce desde 1987. Desde 1989 es Profesor de Historia de la Arquitectura en los Cursos de Arquitectura de Interiores que imparte el Departamento de Construcción y Tecnología Arquitectónicas de la UPM en la Escuela Técnica Superior de Arquitectura.

\section{Resumen}

A pesar de contar la Administración española con los recursos jurídicos suficientes para garantizar una correcta protección del patrimonio arqueológico, el problema principal de dicho patrimonio es su detección y el conocimiento cierto de su existencia. Por otra parte, si bien los nuevos modelos de gestión han mostrado resultados desiguales, hay aspectos muy positivos a destacar. Un debate aún abierto es el de los investigadores con los profesionales en materia de patrimonio arqueológico. También existe la necesidad de contar con equipos multidisciplinarios bien formados, lo cual debería obligar a los colectivos implicados a superar las actuales carencias formativas detectadas, en especial en lo que se refiere a restauración. Se sugiere un esquema elemental de coordinación entre arquitectos y arqueólogos.

\section{Palabras Claves}

Protección del patrimonio arquitectónico, patrimonio arqueológico, arquitectura y arqueología.

\section{Abstract}

Even though the Spanish government has the political resources to give protection to the archeological heritage, the problem with such heritage is the identification and the certain knowledge of its existence. It is necessary that multidisciplinary team's work on this so the parties involved will improve existing deficiencies in the education, especially education on restoration. A coordination plan between architects and archeologist is suggested.

\section{Key words}

Protection of the architectural heritage, archeological heritage, architecture and archeology. 
http://revistaurbanismo.uchile.cl

\section{Sumario}

Introducción

Arqueología y patrimonio arquitectónico: investigación e intervención

Arqueología e intervención en restauración de monumentos

Referencias

\section{Introducción}

En la legislación española existen diversas disposiciones que garantizan la protección del patrimonio arqueológico. Debemos remitirnos, en primer lugar, a la propia Constitución Española que señala en su Artículo 46: "Los poderes públicos garantizarán la conservación y promoverán el enriquecimiento del Patrimonio Histórico, Cultural y Artístico y de los bienes que lo integran cualquiera que sea su régimen jurídico y su titularidad".

También existen disposiciones (Art. 148) referentes a la asunción de competencias para su gestión y protección por parte de las Comunidades Autónomas. La Ley del Suelo se refiere asimismo a dicha protección, otorgando la categoría de Suelo no Urbanizable a aquel que contenga excepcional valor paisajístico, histórico y cultural. La Ley de Patrimonio Histórico Español de 1985 integra, en su título preliminar, dentro del Patrimonio los inmuebles y muebles de interés artístico, histórico, paleontológico, arqueológico, etnográfico, científico o técnico, el patrimonio documental y bibliográfico y los yacimientos y zonas arqueológicas.

Puede consultarse igualmente el Artículo 41 en el que se determina que "Forman parte del Patrimonio Histórico Español los bienes muebles e inmuebles de carácter histórico, susceptibles de ser estudiados con metodología arqueológica, hay sido o no extraídos y tanto si se encuentran en la superficie o en el subsuelo, en el mar territorial o en la plataforma continental. Forman parte asimismo de este patrimonio los elementos geológicos o paleontológicos relacionados con la historia del hombre y sus orígenes y antecedentes". El artículo define asimismo lo que son excavaciones, prospecciones y hallazgos casuales, expresando que las excavaciones y prospecciones deben ser autorizadas por la administración competente, que garantizará la idoneidad de los trabajos científicos relacionados con éstas.

La gestión del Patrimonio Arqueológico queda así en manos de las administraciones públicas competentes en tres niveles: Nacional, a través del Ministerio de Cultura, en lo relacionado con el Patrimonio del Estado y el Patrimonio Nacional; Regional, a través de las Comunidades Autónomas y sus correspondientes Servicios Territoriales de Arqueología (normalmente de ámbito provincial) y Local, a través de las Corporaciones Municipales que, aunque no tienen capacidad expresa en materia de gestión del Patrimonio Arqueológico, pueden -mediante las normativas urbanísticas por ejemplocolaborar de manera muy eficaz a su protección. 
En el municipio de Madrid, por ejemplo se han definido diferentes Zonas Arqueológicas, como la correspondiente al Recinto Histórico, con inclusión de la superficie de la ciudad hasta la cerca del siglo XVIII (1989), o las Terrazas del Manzanares (1990) (Mena 1991: 203-216). Otro buen ejemplo lo puede constituir el caso de Alcalá de Henares (Méndez Madariaga 1991: 267-289). Cuando se haya procedido a la declaración de zonas arqueológicas como Bienes de Interés Cultural (B.I.C.) se redactará un Plan Especial de Protección u otros instrumentos de planeamiento incorporados al Plan General, lo que permite "condicionar las licencias de obra a que a priori se investigue el patrimonio arqueológico subyacente" (Op.Cit. 269). En Alcalá de Henares se establecen cuatro áreas con cuatro grados de protección de mayor a menor interés: A) que incluye zonas en las que está probada la existencia de restos arqueológicos relevantes; B) que cubre áreas de probada existencia de restos que requiere la verificación de su calidad para establecer el destino urbanístico del terreno: C) que incluye zonas de muy probable aparición de restos arqueológicos, aunque puedan encontrarse incompletos o deteriorados; y D) zonas donde se puede suponer que los restos serán de menor importancia o que su localización no está determinada (Op.Cit. 274).

Las actuaciones en la zona A), por ejemplo, requieren la excavación arqueológica preventiva de los solares y la emisión de un Informe Arqueológico relativo a la superficie afectada. Estos trabajos deberán ser llevados a cabo por un Técnico Arqueólogo Colegiado -en el de Doctores y Licenciados en Filosofía y Letras y en Ciencias de Madrid- que deberá contar con el oportuno permiso oficial emitido por la Consejería de Cultura de la Comunidad de Madrid. La financiación de los trabajos arqueológicos correrá a cargo del promotor de las obras, quien podrá solicitar su ejecución de oficio a los Servicios Territoriales de Arqueología si no desea sufragarlos. El resultado de las labores preventivas determinará la calidad del yacimiento y la autorización, en su caso, de las obras previstas. También puede establecerse la oportunidad de una excavación exhaustiva e incluso la conservación in situ de los restos exhumados. En este caso, está prevista la compensación al promotor por parte del Ayuntamiento por la pérdida de aprovechamiento urbanístico (Op.Cit. 278-279).

Por tanto, como vemos, están a disposición de la Administración, en todos sus niveles, los recursos jurídicos suficientes para garantizar una correcta protección del Patrimonio Arqueológico. Sin embargo, el problema principal de buena parte de dicho patrimonio es precisamente su detección y el conocimiento cierto de su existencia. Conocemos desde antiguo yacimientos arqueológicos relevantes, ya excavados y estudiados algunos exhaustivamente- $y$ otros abandonados. Ahora bien, puede existir un importante patrimonio no conocido, porque no forma parte de esa red de yacimientos y no ha sido aún estudiado, ni siquiera inventariado. Uno de los principales objetivos de los distintos servicios de arqueología de las Comunidades Autónomas ha sido, o debería haber sido, la confección de un inventario y la catalogación del patrimonio arqueológico a través de lo que se denomina la Carta Arqueológica.

Los Servicios de Arqueología de la Comunidad de Madrid, desde 1985 -año que se asumen las competencias en materia de arqueología- han centrado buena parte de su actividad en la elaboración de una carta arqueológica completa del territorio autonómico (Velasco Steigrad 1991). La elaboración de las Cartas Arqueológicas 
implica un esfuerzo tanto humano y económico como de tiempo, muy considerable, lo que significa que mientras no se haya redactado completamente, mediante la prospección sistemática del territorio, pueden existir yacimientos arqueológicos relevantes no documentados ni controlados (1).

\section{Arqueología y patrimonio arquitectónico: investigación e intervención}

Antes del desarrollo de los actuales modelos de gestión del Patrimonio Arqueológico podía ser frecuente que, por ejemplo, durante la ejecución de obras públicas o de edificación, o en trabajos de restauración de monumentos, apareciesen restos arqueológicos de interés. Se paralizaban entonces las obras y se procedía a la realización de lo que suele denominarse una Excavación Arqueológica de Urgencia.

De su ejecución podrían plantearse diversos problemas: en primer lugar, podía producirse un perjuicio económico derivado de la propia paralización de los trabajos e incluso un perjuicio social por el retraso en la ejecución de infraestructuras fundamentales. Se podía producir igualmente un perjuicio científico, porque era plausible la destrucción de una parte de los restos antes de proceder a su estudio o porque la celeridad de los trabajos obligaba a excavar de manera precaria y no sistemática. Incluso en algunos casos se llegaba a ocultar el hallazgo para evitar problemas con la administración y se destruía sistemáticamente el yacimiento. Por otro lado, estas excavaciones de urgencia eran ejecutadas directa o indirectamente por la propia administración -puesto que no existía un colectivo de arqueólogos que ejerciese libremente su profesión- lo que se traducía además en una acusada tardanza a la hora de acometer los trabajos.

Desde hace más de una década se ha venido planteando progresivamente un modelo de gestión diferente, basado en el establecimiento de Zonas Arqueológicas Protegidas en las que, como hemos visto en el ejemplo de Alcalá de Henares, de manera previa a cualquier intervención deben realizarse trabajos de prospección intensiva o de excavación preventiva. Un caso similar puede ser el de las obras de restauración de monumentos o edificios que contengan valores históricos o artísticos en los que suele recomendarse, cuando menos, la realización de un Seguimiento Arqueológico de las obras. Entre las ventajas de este modelo, que no siempre ha recibido elogios por la totalidad del colectivo de arqueólogos -en especial por parte de los docentes- y cuya aplicación ha mostrado, es cierto, desiguales resultados, pueden destacarse las siguientes:

$1^{\circ}$. Se han venido estableciendo con mayor claridad las zonas de interés arqueológico, con lo que han podido coordinarse los trabajos de excavación o documentación preventiva con antelación, sin necesidad de paralizar obras ya iniciadas. Se ha excavado más y con mejor financiación, y desde luego, con menor perjuicio sobre intereses de terceros.

$2^{\circ}$. La financiación de los trabajos ha dejado de ser necesariamente pública y ha pasado a ser responsabilidad de los promotores privados, con lo que se han aumentado de manera general los recursos empleados en materia de arqueología, 
pudiendo reservarse los de origen público, siempre escasos, a proyectos de investigación muy relevantes, a la confección de las Cartas Arqueológicas y a la protección de los yacimientos más importantes o de aquellos que demandaban actuaciones preventivas de forma más perentoria.

$3^{\circ}$. Se ha desarrollado un nuevo colectivo profesional, formado por los arqueólogos que se encargan de la dirección y ejecución de estas intervenciones de manera inmediata, por lo que la ejecución de las labores preventivas no depende de la disponibilidad de la administración, cuyos servicios territoriales presentan, normalmente, escasa dotación de personal técnico.

En este sentido creemos conveniente recordar que el desarrollo de la Arqueología de Intervención en el ámbito urbano y en el de la construcción de infraestructuras "pocas veces ha sido objeto de enfrentamientos entre intereses contrapuesto" y "más aún ha servido para despertar una conciencia ciudadana a favor de la protección del patrimonio" (Méndez Madariaga 1991: 269). Salvo en casos excepcionales, como la célebre y reciente polémica en torno a los restos de la Plaza de Oriente de Madrid -de la que por otra parte se habrá de esperar a la publicación de la totalidad de los resultados obtenidos y de los informes realizados antes de emitir cualquier juicio- las intervenciones arqueológicas preventivas en el medio urbano se han venido efectuando en general con claridad y eficiencia, y alejadas, desde luego, de los enfrentamientos que desde ámbitos ajenos a la propia disciplina y sus profesionales han sido llevados a la arena política en beneficio de intereses no estrictamente científicos, sean o no legítimos.

Por otra parte, el desarrollo de esta Arqueología Profesional, no ha interferido en absoluto en la política de investigación científica y en la excavación arqueológica de yacimientos relevantes, cuya financiación ha seguido dependiendo de las subvenciones con cargo a los presupuestos de instituciones y organismos públicos, y cuyos directores y ejecutores han seguido siendo, como siempre, profesores universitarios e investigadores adscritos a Museos o Institutos Científicos, algunos de los cuales han incidido en el escaso interés de las intervenciones profesionales así como en el bajo rendimiento y falta de preparación de los arqueólogos designados para llevarlas a término, arqueólogos, que por otra parte, y creemos muy honesto recordarlo, se han formado todos sin excepción en la Universidad, bajo la tutela de aquellos entre los que ahora se encuentran sus principales críticos.

En general hemos asistido a un debate, todavía sin cerrar, entre ambos sectores investigadores $y$ profesionales- pero sobre el que se han ido estableciendo poco a poco algunos aspectos de interés general para todos, conviniéndose en la necesidad de mejorar la capacidad investigadora del profesional, fomentar la publicación de los resultados obtenidos y coordinar las intervenciones de urgencia en proyectos generales de interés científico que redunden en un ampliación del corpus teórico y metodológico de la arqueología española.

En general podría recomendarse un "mejor desarrollo científico de la Arqueología de Gestión y una mayor promoción social de la Arqueología de Investigación" (Burillo et al. 1994:37). Aun cuando admitamos que no puede establecerse una dicotomía entre 
http://revistaurbanismo.uchile.cl

Arqueología de Investigación y Arqueología de Gestión sino entre modelos de Gestión del Patrimonio Arqueológico (Hornos Mata 1994: 12), no debe olvidarse que la arqueología profesional se desarrolla en parámetros distintos de la investigación científica en tanto que la excavación debe realizarse en el menor tiempo posible para facilitar el desarrollo de las obras que la generaron o para permitir la modificación puntual o parcial de los proyectos originales con celeridad. No pueden obviarse determinadas prioridades de nuestra sociedad atendiendo exclusivamente al interés de un colectivo concreto.

Es posible, el creciente desarrollo de la arqueología profesional así lo demuestra, compaginar los intereses de promotores públicos o privados con la protección eficaz del patrimonio arqueológico; es posible aunar calidad en la ejecución y eficiencia científica en cuantas intervenciones se lleven a cabo. Para ello, es imprescindible hacer comprender a la sociedad en su conjunto, desde la tolerancia y la formación, la importancia de preservar y conocer nuestro patrimonio arqueológico.

\section{Arqueología e intervención en restauración de monumentos (2)}

El hecho de que hayamos tratado arriba algunos aspectos relativos al ejercicio de la arqueología como actividad profesional liberal nos obliga a incluir aquí algunas reflexiones en torno a uno de los ámbitos donde este ejercicio libre va a experimentar seguramente un mayor crecimiento. Nos referimos, a la participación del arqueólogo en los equipos multidisciplinares que formados por arquitectos, historiadores, aparejadores, ingenieros y otros especialistas permiten abordar con la suficiente competencia la tarea de intervenir en edificios históricos.

Es hoy frecuente constatar la existencia de un cierto grado de desconfianza en las relaciones que rigen la colaboración profesional entre arqueólogos, y podemos afirmar que posiblemente obedece más a la mutua ignorancia de la clase de labores a acometer y de la metodología empleada para su resolución por parte de los miembros de estos colectivos que a la existencia de un verdadero conflicto de intereses profesionales. Muchos de los problemas que se plantean están relacionados más directamente con la estructura del organigrama de gestión del patrimonio que los propios profesionales se afanan por elaborar que con la aceptación final de las prioridades en la ejecución de una restauración, que no son otras, no lo olvidemos, que las que impone la salvaguarda de los valores del edificio en conjunción con el destino funcional que la propia sociedad, en su conjunto y no sólo una parte de la misma -los especialistas- le quiere dar. Ahí se encuentra el verdadero vértice de la pirámide. Arqueólogos, historiadores, arquitectos, están al servicio del Patrimonio y no al revés. 
Por otra parte, conviene recordar que, hoy por hoy, en lo que se refiere a conservación e intervención en el patrimonio histórico inmueble, el colectivo profesional en el que se deposita la responsabilidad de las labores de redacción de los proyectos y dirección de las ejecuciones es, como parece lógico, el de los arquitectos. Dejando a un lado los problemas relacionados con la definición de las estrategias generales, el establecimiento de las prioridades y la financiación de las intervenciones, los verdaderos gestores del patrimonio histórico inmueble en España son los arquitectos. Por ello es especialmente importante despertar en este colectivo un mayor interés en relación con la problemática de la actuación arqueológica. Si bien es cierto que cada día es mayor el número de arquitectos formados o interesados en recibir formación específica en este campo -como lo atestigua el creciente desarrollo de módulos sobre arqueología en los cursos de postgrado por ejemplo- es igualmente importante reconocer que apenas se instruye a los estudiantes de las Escuelas de Arquitectura en relación con las características de las intervenciones arqueológicas en obras de conservación, restauración o rehabilitación. La reciente reforma -aún en fase de desarrollo- de los nuevos planes de estudios de la Arquitectura debería proporcionar el marco idóneo para atajar las actuales carencias, aunque se hiciese exclusivamente sobre la posibilidad de que figurase en los currículos académicos alguna asignatura optativa.

Por todo ello, nos ha parecido oportuno incluir aquí un esquema elemental de coordinación entre arquitectos y arqueólogos, a tener en cuenta durante las distintas fases de definición, establecimiento de criterios de intervención, redacción de proyectos de restauración y dirección de la ejecución de las obras en edificios de interés histórico, artístico o arquitectónico. La necesidad de contar con los equipos multidisciplinares bien formados que requiere la adecuada gestión de nuestro abundante patrimonio debería obligar a todos los colectivos implicados a poner los medios para atajar las actuales carencias formativas detectadas, en especial en lo que se refiere a restauración. Es obvio señalar que precisamente esta publicación pretende, por supuesto desde una actitud de sincera modestia, colaborar en dicha tarea, aportando algunas orientaciones en lo relativo al ámbito de la docencia y facilitando la reflexión sobre algunos de los problemas suscitados en el campo del ejercicio profesional. 
$\mathrm{http} / / /$ revistaurbanismo.uchile.cl

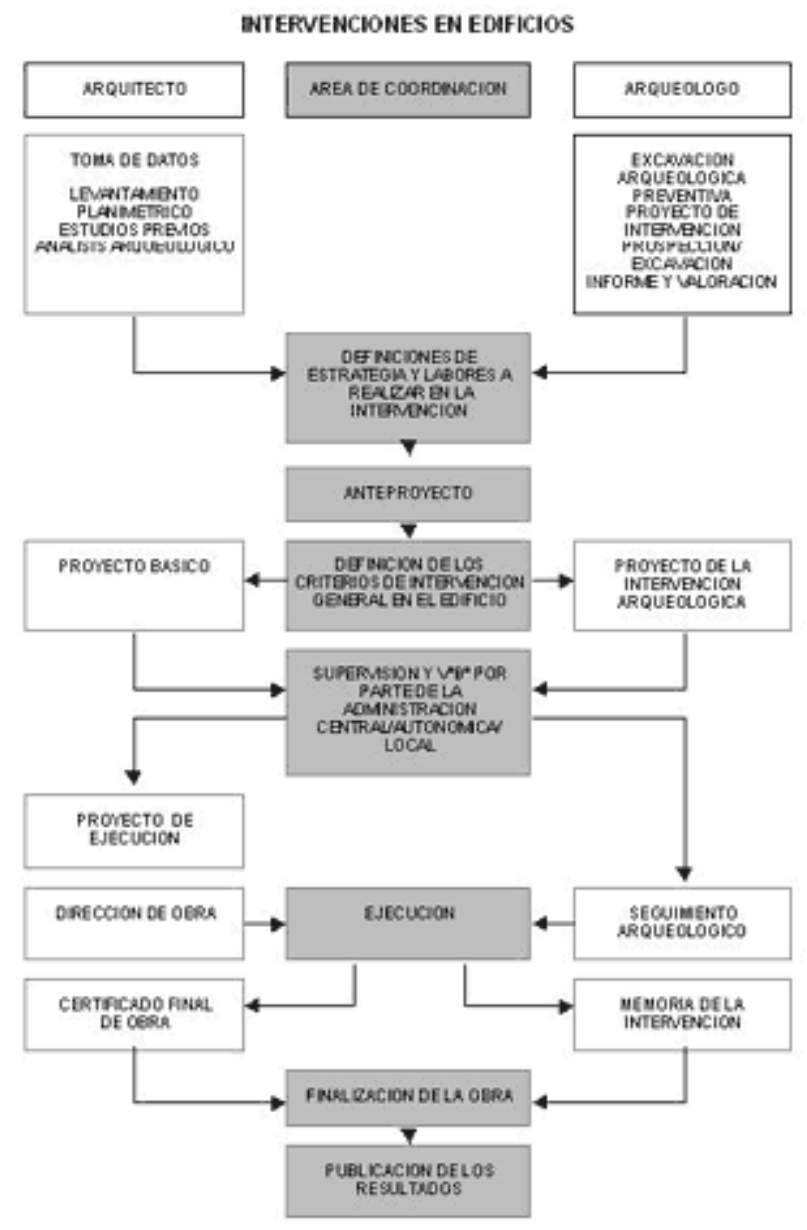

\section{Referencias}

\section{Bibliografía}

BURILLO, F. IBAÑEZ, E.J. Y C. POLO (1994). El Patrimonio Arqueológico en el medio rural. Conservación arqueológica. Reflexión y debate sobre teoría y práctica ( $p p$. 3649). Instituto Andaluz del Patrimonio Histórico-Instituto Español de Arquitectura. 141 p.

COMISIÓN PROFESIONAL DE ARQUEOLOGÍA DEL COLEGIO OFICIAL DE DOCTORES Y LICENCIADOS EN FILOSOFÍA Y LETRAS Y EN CIENCIAS DE MADRID (1990). Defensa y Gestión del Patrimonio Arqueológico. Madrid, 33 p.

COMISIÓN PROFESIONAL DE ARQUEOLOGÍA DEL COLEGIO OFICIAL DE DOCTORES Y LICENCIADOS EN FILOSOFÍA Y LETRAS Y EN CIENCIAS DE MADRID (1993). LoS mecanismos de la arqueología de intervención en la Comunidad de Madrid. Boletín Colegio Oficial Doctores y Licenciados de Madrid, núm. 45 (pp. 26-30). 


\section{REVISTA DE URBANISMO

http://revistaurbanismo.uchile.cl

COMISIÓN PROFESIONAL DE ARQUEOLOGÍA DEL COLEGIO OFICIAL DE DOCTORES Y LICENCIADOS EN FILOSOFÍA Y LETRAS Y EN CIENCIAS DE MADRID Y F. VELASCO STEIGRAD (1993). Hacia un modelo de gestión y desarrollo profesional. Boletín C.D.L., núm. 41 (pp. 22-26).

HORNOS, MATA, F. (1994). Reflexiones acerca del Patrimonio Arqueológico inmueble y su conservación. Conservación arqueológica. Reflexión y debate sobre teoría y práctica (pp. 10-17). Instituto Andaluz del Patrimonio Histórico-Instituto Español de Arquitectura. $141 \mathrm{p}$.

MENA MUÑOZ, Pilar (1991). Arqueología urbana en el término municipal de Madrid (1985-1990). Arqueología, Paleontología y Etnografía, núm. 1 (pp. 201-216) Madrid: Comunidad Autónoma de Madrid.

MÉNDEZ MADARIAGA, Antonio (1991) La protección del Patrimonio Arqueológico. El ejemplo de Alcalá de Henares. Arqueología, Paleontología y Etnografía, núm. 2 (pp. 267-290). Madrid: Comunidad Autónoma de Madrid.

VELACO STEIGRAD, Fernando (1991). El programa de carta arqueológica en la Comunidad. Arqueología, Paleontología y Etnografía, núm. 1 (pp. 257-280). Madrid: Comunidad Autónoma de Madrid.

\section{Notas}

(1) N. de R. R.U.: La parte tercera del libro citado desde donde se extrae este escrito, incluye un estudio exhaustivo en relación con el régimen legal de las intervenciones arquitectónicas en los yacimientos arqueológicos, incluyendo un anejo con la legislación vigente sobre el tema.

(2) N. de R. R.U.: Un capítulo del libro citado desde donde se extrae este escrito, está dedicado a la intervención del arqueólogo en los proyectos de restauración y rehabilitación del patrimonio histórico, artístico o arquitectónico.

N. de R.: Este escrito es un extracto autorizado por los autores y Ediciones Munilla-Lería, del libro: Maldonado Ramos, Luis, y Vela Cossío, Fernando (1998), De Arquitectura y Arqueología, Ediciones MunillaLería, Madrid, 1998, 173 páginas ilustradas. I.S.B.N.: 84-89150-21-4. (Extracto: pp.81-89). 